Article

\title{
Origanum vulgare L. Essential Oil as a Potential Anti-Acne Topical Nanoemulsion-In Vitro and In Vivo Study
}

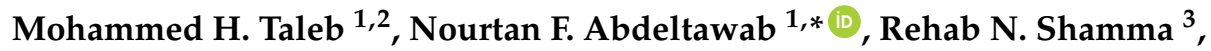 \\ Sherein S. Abdelgayed ${ }^{4}$, Sarah S. Mohamed ${ }^{5}$ (i), Mohamed A. Farag ${ }^{6,7}$ and \\ Mohammed A. Ramadan ${ }^{1}$ \\ 1 Department of Microbiology and Immunology, Faculty of Pharmacy, Cairo University, Cairo 11562, Egypt; \\ almataleb21@gmail.com (M.H.T.); m_ramdan56@hotmail.com (M.A.R.) \\ 2 Department of Pharmaceutics and Pharmaceutical Technology, Faculty of Pharmacy, Al-Azhar \\ University-Gaza, PO Box 1277, Gaza 79702, Palestine \\ 3 Department of Pharmaceutics and Industrial pharmacy, Faculty of Pharmacy, Cairo University, Cairo 11562, \\ Egypt; rehab.shamma@pharma.cu.edu.eg \\ 4 Department of Pathology, Faculty of Veterinary Medicine, Cairo University, Cairo 12211, Egypt; \\ sherein.abdelgayed@vet.cu.edu.eg \\ 5 Department of Pharmacology and Toxicology, Faculty of Pharmacy, Cairo University, Cairo 11562, Egypt; \\ sarah.elsayed@pharma.cu.edu.eg \\ 6 Department of Pharmacognosy, Faculty of Pharmacy, Cairo University, Cairo 11562, Egypt; \\ mfarag73@yahoo.com \\ 7 Department of Chemistry, School of Sciences \& Engineering, The American University in Cairo, \\ Cairo 11853, Egypt \\ * Correspondence: nourtan.abdeltawab@pharma.cu.edu.eg; Tel.: +20-112-205-5115
}

Received: 18 July 2018; Accepted: 20 August 2018; Published: 28 August 2018

check for updates

\begin{abstract}
Antibiotics are often prescribed in acne treatment; however, Propionibacterium acnes and Staphylococcus epidermidis, the two of the major acne-associated bacteria, developed antibiotic resistance. Essential oils (EOs) present a natural, safe, efficacious and multifunctional alternative treatment. This study aimed to assess the potential anti-acne activity of selected seven EOs commonly used in Mediterranean folk medicine. Antimicrobial activity screening of these oils showed oregano to exhibit the strongest antimicrobial activity with minimum inhibitory concentration (MIC) of $0.34 \mathrm{mg} / \mathrm{mL}$ and minimum bactericidal concentration (MBC) of $0.67 \mathrm{mg} / \mathrm{mL}$ against P. acnes; and MIC of $0.67 \mathrm{mg} / \mathrm{mL}$ and $\mathrm{MBC}$ of $1.34 \mathrm{mg} / \mathrm{mL}$ against $S$. epidermidis. The composition of the most effective EOs (oregano and thyme) was determined using gas chromatography-mass spectrometry (GC-MS). Monoterpenoid phenols predominated oregano and thyme EO with thymol percentile 99 and 72, respectively. Thymol showed MIC $0.70 \mathrm{mg} / \mathrm{mL}$ against both P. acnes and S. epidermidis whereas MBC was 1.40 and $2.80 \mathrm{mg} / \mathrm{mL}$ against $P$. acnes and S. epidermidis, respectively. Moreover, oregano exhibited the strongest anti-biofilm effect against $S$. epidermidis with MBIC $1.34 \mathrm{mg} / \mathrm{mL}$ and killing dynamic time of 12 and $8 \mathrm{~h}$ against $P$. acnes and S. epidermidis, respectively. Oregano, the most effective EO, was formulated and tested as a nanoemulsion in an acne animal mouse model. The formulation showed superior healing and antimicrobial effects compared to the reference antibiotic. Collectively, our data suggested that oregano oil nanoemulsion is a potential natural and effective alternative for treating acne and overcoming the emerging antibiotic resistance.
\end{abstract}

Keywords: acne vulgaris; essential oils; oregano; thymol; S. epidermidis; P. acnes; antimicrobial activity; nanoemulsion; antibiotic resistance 


\section{Introduction}

Acne vulgaris is the 8 th most prevalent disease and second top skin disease globally [1]. Adolescents of both genders are typically affected by acne. Acne in adolescents can cause psychological disorders and in severe cases can lead to depression [2]. Acne is a multifactorial disease characterized by pathological alteration in pilosebaceous units of the neck and upper trunk. It results in the formation of non-inflammatory comedones and inflammatory lesions such as papules, pustules, and nodules [3]. Two bacteria are associated with acne pathogenesis: Propionibacterium acnes and Staphylococcus epidermidis [4]. These bacteria are part of normal human skin microbiota, but if dysbiosis occurs, infection of pilosebaceous units can lead to acne. Accordingly, most anti-acne drugs are directed against $P$. acnes and S. epidermidis infection and associated inflammatory responses. Anti-acne therapy includes systemic and topical therapies. Topical therapies include comedolytic agents, anti-inflammatory agents and antibiotics [5]. Bacterial resistance accompanies topical anti-acne antibiotics. Resistance to topical anti-acne antibiotics is attributed to multiple factors, including use of repeated single antibiotic, sub-inhibitory concentrations, or use over extended time [6,7].

To overcome the emerging resistance to conventional antibiotics, alternative natural antimicrobial agents have been investigated. Essential oils (EOs) of aromatic plants such as oregano, tea tree oil, lemongrass, and thyme have antimicrobial activities that can be used as a natural alternative [8]. The antimicrobial activity of these EOs is attributed to their major constituents: Monoterpenoid phenols. In addition, EOs' minor constituents, such as the monoterpene hydrocarbons, $\gamma$-terpinene, and $p$-cymene, may contribute to the antibacterial activity of these oils $[9,10]$. Some studies show that a few EOs have anti-acne activity; tea tree oil is commercially used [11]. Therefore, this study tested the anti-acne potential of seven EOs used in Mediterranean folk medicine: Oregano (Origanum vulgare), thyme (Thymus vulgaris), lemongrass (Cymbopogon citratus), tea tree (Melaleuca alternifolia), mentha (Mentha piperita), lavender (Lavendula anguestifolia), and chamomile (Matricaria recutita). The Mediterranean region is one of the largest producers of these aromatic plants. Its favorable climatic and cultivation conditions enhance the quality of EO constitutes [12]. We assessed the antimicrobial activity of the above-selected EOs against acne-causing bacteria in vitro.

Another aim of this study was to develop a pharmaceutical formulation of the EO with the highest antimicrobial effect. Based on our in vitro antibacterial results of tested EOs against acne-causing bacteria, we formulated oregano EO as a nanoemulsion formula. Nanoemulsions offer enhanced solubilization capacity for hydrophobic, poorly soluble drugs as typical in the case of EOs [13]. In this study, we assessed the healing and antimicrobial activity of the developed nanoemulsion of the most effective EO in vivo in an acne mouse model as a potential new formulation for acne treatment.

\section{Results}

\subsection{Screening of Antibacterial Activity of Tested EOs Using Agar Disc Diffusion Method}

The selected seven EOs have been screened for their antibacterial activities against $P$. acnes and S. epidermidis using the disc diffusion test. The results were represented as the diameter of inhibition zone (Figure 1 and Table S1). P. acnes and S. epidermidis were susceptible to oregano and thyme EOs with a zone of inhibition (ZOI) ranging from 16 to $32 \mathrm{~mm}$ larger than those of erythromycin and clindamycin reference antibiotics (Figure 1). While lemongrass and tea tree showed moderate ZOI from 9-17 mm, lavender, mentha, chamomile EOs failed to inhibit the growth of both bacteria (Figure 1 and Table S1). The two studies' positive controls (erythromycin and clindamycin) showed ZOI ranging from 10 to $20 \mathrm{~mm}$. The negative control vehicle dimethylsulfoxide (DMSO) showed no inhibition against both bacteria. 


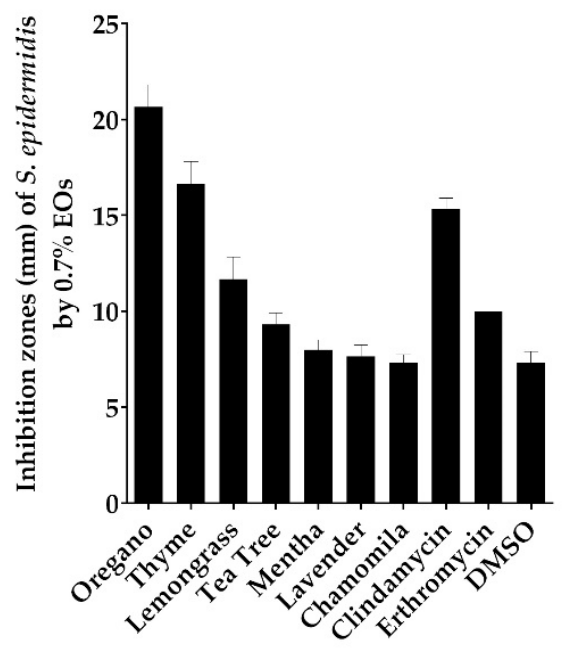

(a)

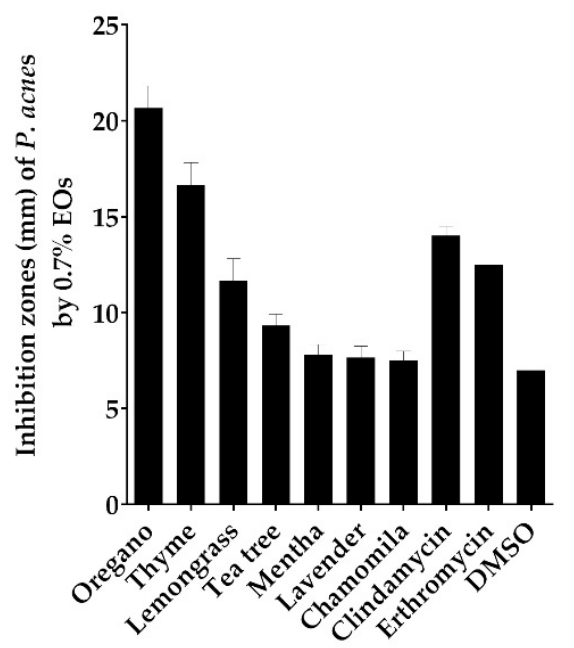

(c)

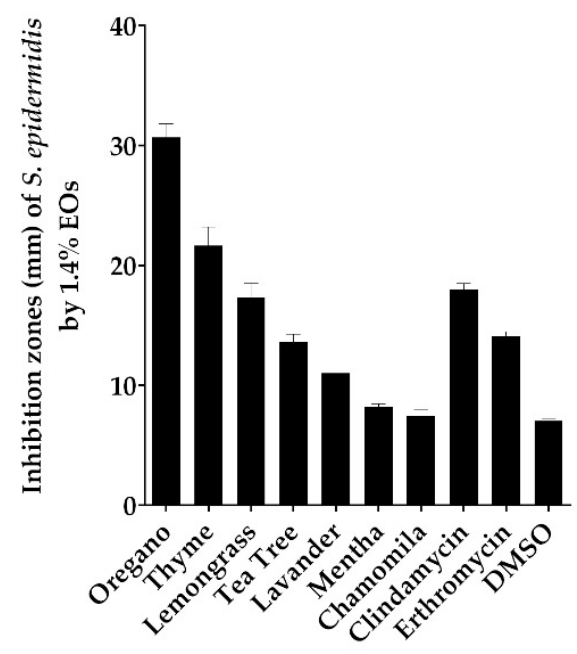

(b)

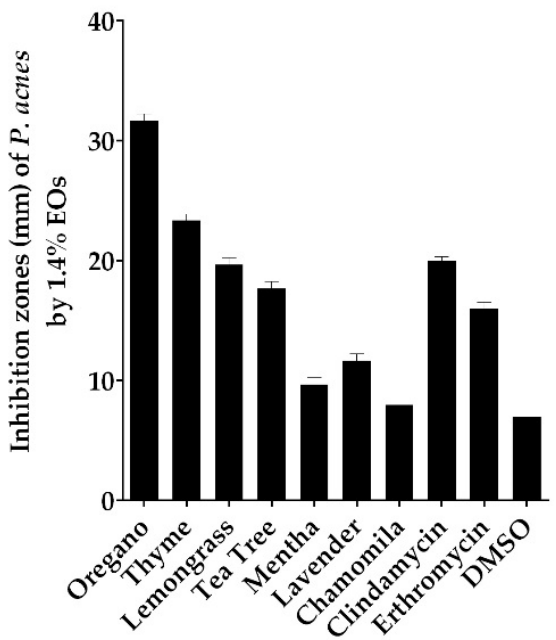

(d)

Figure 1. Oregano EO exhibited the largest inhibition zone among the tested oils. Antibacterial activity of the screened EOs using agar disc diffusion method against (a) S. epidermidis with EOs at concentration of $0.7 \%$; (b) S. epidermidis with EOs at concentration of $1.4 \%$; (c) P. acnes with EOs at concentration of $0.7 \%$; (d) P. acnes with EOs at concentration of $1.4 \%$. Data is represented as means of inhibition zones $(\mathrm{mm}) \pm \mathrm{SD}$. Controls used were clindamycin and erythromycin as positive control, while DMSO as negative control.

\subsection{Antimicrobial Activity of the Tested EOs Using Minimal Inhibitory Concentration (MIC) Method}

Minimal inhibitory concentration (MIC) test results confirmed that the most potent EOs against P. acnes and S. epidermidis were oregano, thyme, lemongrass and tea tree oils (Table 1). Oregano EO displayed lowest MIC values of $0.34,0.67 \mathrm{mg} / \mathrm{mL}$ against P. acnes and S. epidermidis, respectively. Second to oregano was thyme EO, exhibiting an MIC of $0.65,1.30 \mathrm{mg} / \mathrm{mL}$ against P. acnes and $S$. epidermidis, respectively. Consequentially, oregano, thyme, lemongrass, and tea tree EOs were selected for determining minimum bactericidal concentration (MBC), demonstrating the most effective inhibition against $P$. acnes and $S$. epidermidis by disc diffusion and MIC assays. 
Table 1. Minimal inhibitory concentration (MIC) of the seven tested EOs against S. epidermidis and P. acnes.

\begin{tabular}{ccc}
\hline \multirow{2}{*}{ Essential Oils } & \multicolumn{2}{c}{ MIC } \\
\cline { 2 - 3 } & S. epidermidis $(\mathbf{m g} / \mathbf{m L})$ & P. acnes $(\mathbf{m g} / \mathbf{m L})$ \\
\hline Oregano & 0.67 & 0.34 \\
Thyme & 1.30 & 0.65 \\
Lemongrass & 1.22 & 1.22 \\
Tea tree & 1.27 & 1.28 \\
Lavender & 2.52 & 2.52 \\
Mentha & 5.28 & 2.60 \\
Chamomile & 6.22 & 3.18 \\
\hline
\end{tabular}

\subsection{The Bactericidal and Anti-Biofilm Activities of the Tested EOs}

The bactericidal activity of the four EOs with the top ZOIs and MICs were tested against acne-causing bacteria. Oregano EO at a concentration of 0.67 and $1.34 \mathrm{mg} / \mathrm{mL}$ inhibited the growth of P. acnes and S. epidermidis, respectively (Table 2). Tea tree EO exhibited the least bactericidal activity at 2.558 and $5.116 \mathrm{mg} / \mathrm{mL}$ against $P$. acnes and S. epidermidis, respectively. Next, the four-selected EOs were assayed for anti-biofilm activity against S. epidermidis (Table 3). Oregano EO inhibited biofilm formation by $S$. epidermidis at its bactericidal concentration $(1.34 \mathrm{mg} / \mathrm{mL})$. In contrast, the least effective EO was tea tree oil was unable to inhibit biofilm formation of $S$. epidermidis at concentration up to $2.56 \mathrm{mg} / \mathrm{mL}$ equivalent to $0.28 \% v / v$ (Table 3 ).

Table 2. Minimal bactericidal concentrations (MBC) of the selected EOs against S. epidermidis and P. acnes.

\begin{tabular}{ccc}
\hline \multirow{2}{*}{ Essential Oils } & \multicolumn{2}{c}{ MBC } \\
\cline { 2 - 3 } & S. epidermidis $(\mathbf{m g} / \mathbf{m L})$ & P. acnes $(\mathbf{m g} / \mathbf{m L})$ \\
\hline Oregano & 1.34 & 0.672 \\
Thyme & 2.60 & 1.30 \\
Lemongrass & 2.44 & 2.44 \\
Tea tree & 5.10 & 2.55 \\
\hline
\end{tabular}

Table 3. Minimum biofilm inhibitory concentration (MBIC) of the selected EOs against S. epidermidis.

\begin{tabular}{cc}
\hline Essential Oils & MBIC \\
\cline { 2 - 2 } & $\mathbf{m g} / \mathbf{m L}$ \\
\hline Oregano & 1.344 \\
Thyme & 2.60 \\
Lemongrass & 2.44 \\
Tea tree & 2.55 \\
\hline
\end{tabular}

\subsection{Killing Dynamics of Oregano EO against S. epidermidis and P. acnes}

Since our results of agar disc diffusion, MIC, MBC and MBIC assays showed that oregano EO was superior, the dynamics of oregano EO's killing activity was determined. MIC, 2MIC and 4MIC of oregano EO showed significant reduction in the number of both P. acnes and S. epidermidis after $4 \mathrm{~h}$ of application (Figure 2). Oregano EO killing capacity against S. epidermidis was higher than P. acnes at 8 and $12 \mathrm{~h}$ (Figure 2). Oregano EO volatile constituents were determined using gas chromatography-mass spectrometry (GC-MS) analysis to pinpoint active agents in oregano EO likely to mediate the observed anti-acne effects. 


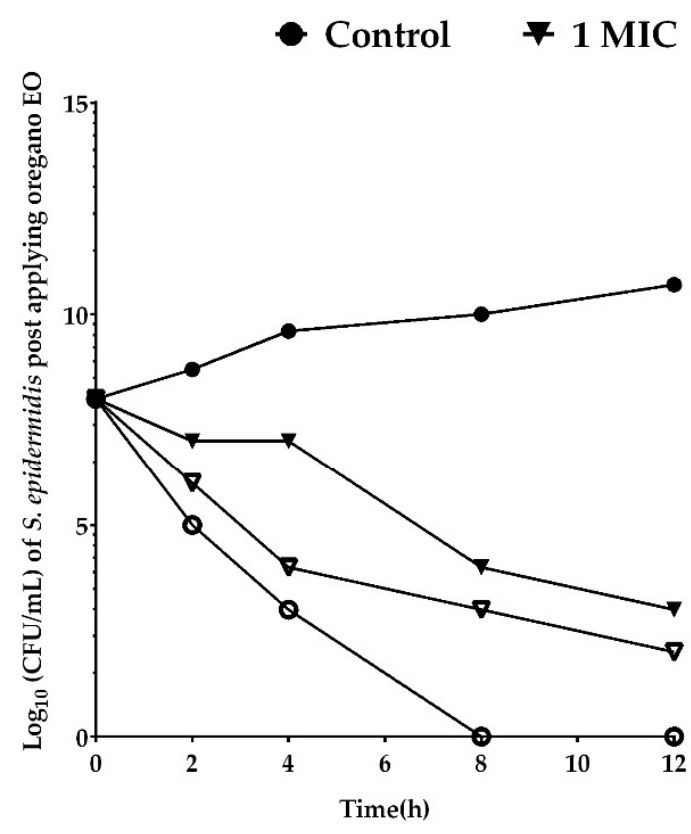

(a)

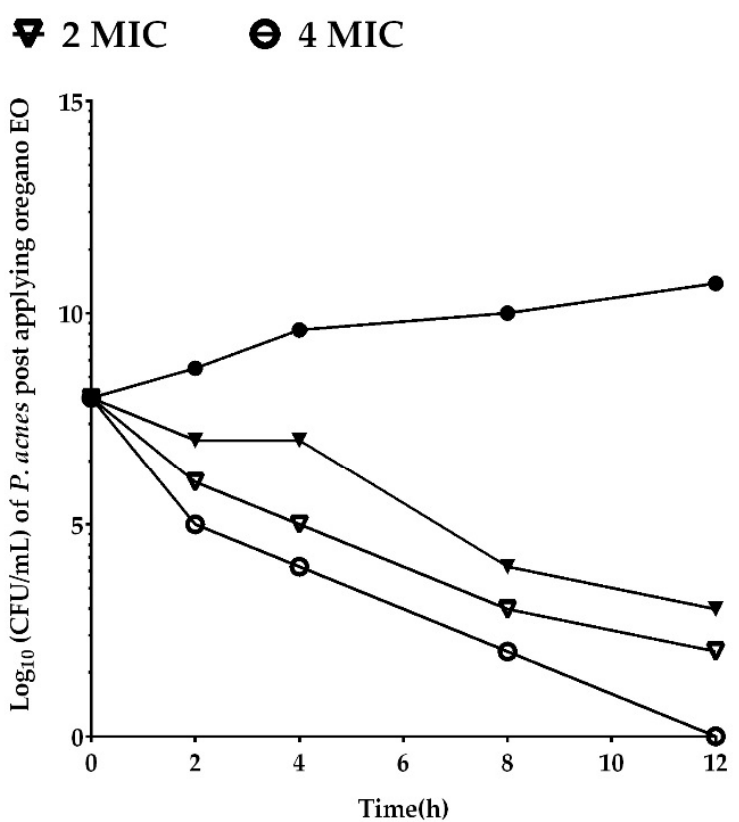

(b)

Figure 2. Oregano EO inhibited the growth of S. epidermidis faster than P. acnes. Oregano EO at concentrations of $0.672,1.34,2.68 \mathrm{mg} / \mathrm{mL}(1,2,4 \mathrm{MIC})$ and no EO control was used for assaying the killing rate of bacterial cells at $0,2,4,8$ and $12 \mathrm{~h}$ and expressed as the surviving bacteria $\left(\log _{10} \mathrm{CFU} / \mathrm{mL}\right)$ at different exposure times. We used starting bacterial suspension concentration $10^{8} \mathrm{CFU} / \mathrm{mL}$. Oregano EO killing rate against (a) S. epidermidis and (b) P. acnes.

\subsection{Chemical Composition of Oregano and Thyme EOs}

Both oregano and thyme belong to the same family (Lamiaceae), producing aromatics as major essential oil constituents. Our GC-MS analysis of oregano and thyme EO volatile constitutes showed that the major volatile compound was thymol (Table 4 and Figure S1). Thymol represented $99.44 \%$ of oregano $\mathrm{EO}$ and $72 \%$ of thyme volatile compounds. Other volatiles identified were at much-lower levels in both oils and include $p$-cymene, cineole and $\gamma$-terpinene (Table 4 ).

Table 4. GC-MS analysis of volatile compounds in oregano and thyme EOs.

\begin{tabular}{|c|c|c|c|c|}
\hline Compound & Oregano EO Content \% & Thyme EO Content \% & Retention Time & Retention Index \\
\hline Thymol $^{\mathrm{a}}$ & 99.44 & 72.08 & 12.81 & 1280 \\
\hline$p$-cymene ${ }^{\text {a }}$ & 0.2 & 25.18 & 8.79 & 1005 \\
\hline$\gamma$-terpinene & 0.03 & 2.52 & 9.31 & 1038 \\
\hline$\alpha$-Thujene & 0.01 & 0.01 & 7.15 & 911 \\
\hline Cineole $^{\mathrm{a}}$ & 0.06 & - & 8.96 & 1012 \\
\hline Thymol isomer & 0.07 & 0.00 & 12.68 & 1274 \\
\hline Isocaryophyllene ${ }^{a}$ & 0.04 & - & 14.34 & 1428 \\
\hline Carvacrol & - & 0.07 & 12.67 & 1272 \\
\hline
\end{tabular}

${ }^{a}$ represents volatiles compared with authentic standard.

The antimicrobial activity data showed that oregano EO exhibited the largest inhibition zones and MIC among the tested seven oils. Oregano EO displayed the best MBC and MBIC among selected top four EOs, along with rapid killing rates of both tested bacteria. Moreover, our GC-MC analysis showed that thymol content in oregano EO was higher than thyme EO, suggesting that thymol might be the reason for oregano superior antimicrobial activities. Therefore, we next aimed to assay thymol antimicrobial activity compared to oregano and thyme EOs. 


\subsection{Antimicrobial Activity of Thymol Using In Vitro Disc Diffusion, MIC, MBC and MBIC Assays}

The antimicrobial activity of thymol, the main volatile constituent of oregano and thyme EOs, was assayed. Using the disc diffusion method, thymol at $0.7 \%$ and $1.4 \%$ concentration inhibited the growth of S. epidermidis and P. acnes significantly higher than erythromycin (inhibition zone $>19 \mathrm{~mm}$ ) (Figures 1 and 3, Table S1). On assaying of the MIC of thymol against S. epidermidis and P. acnes, oregano and thyme were found to be superior to thymol (Tables 1 and 5). Similarly, MBC of thymol against P. acnes was lower than oregano and thyme. MBC of thymol against S. epidermidis was intermediate between oregano and thyme EOs (Tables 2 and 5). Finally, thymol antibiofilm activity against S. epidermidis was lower than oregano, thyme, lemongrass and tea tree EOs (Tables 3 and 5).

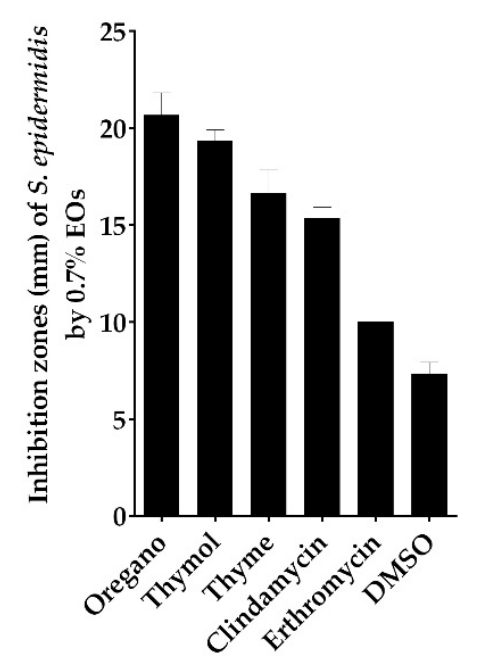

(a)

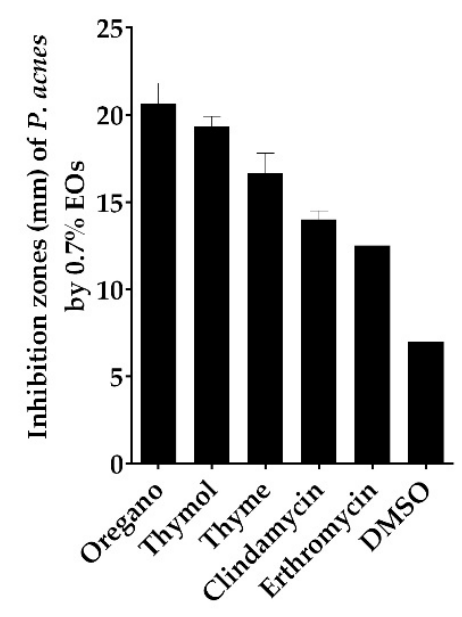

(c)

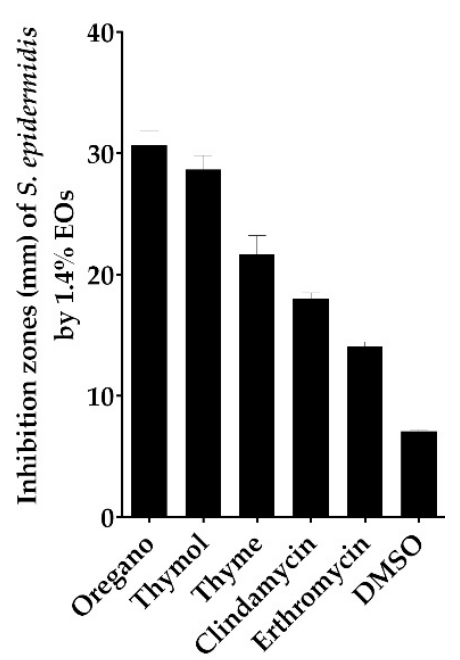

(b)

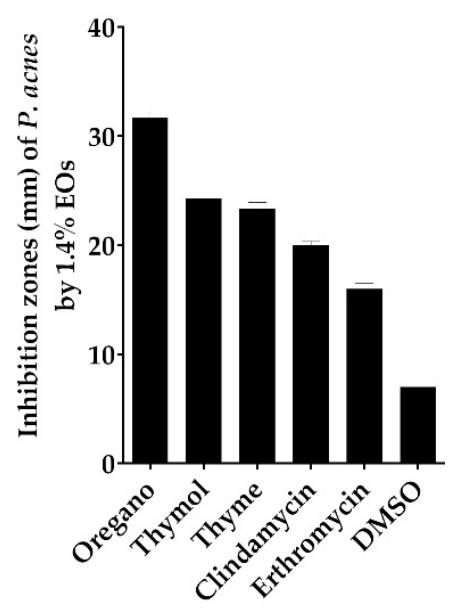

(d)

Figure 3. Thymol exhibited lower inhibition zone than oregano EO. Antibacterial activity of thymol and the most bioactive EOs using disc diffusion method (zone of inhibition in $\mathrm{mm}$ ) against (a) S. epidermidis with thymol and EOs at concentration of $0.7 \%$; (b) S. epidermidis with thymol and EOs at concentration of $1.4 \%$; (c) P. acnes with thymol and EOs at concentration of $0.7 \%$; (d) P. acnes with thymol and EOs at concentration of $1.4 \%$. Data is represented as means of inhibition zones $(\mathrm{mm}) \pm \mathrm{SD}$. Controls used were clindamycin and erythromycin as positive control with DMSO as negative control. 
Table 5. MIC, MBC and MBIC of thymol against S. epidermidis and P. acnes.

\begin{tabular}{cccc}
\hline Acne-Causing Bacteria & MIC $(\mathbf{m g} / \mathbf{m L})$ & MBC $(\mathbf{m g} / \mathbf{m L})$ & MBIC $(\mathbf{m g} / \mathbf{m L})$ \\
\hline S. epidermidis & 0.7 & 2.8 & 2.8 \\
P. acnes & 0.7 & 1.4 & - \\
\hline
\end{tabular}

Despite the predominance of thymol in oregano EO, in vitro antimicrobial assays showed that oregano EO was superior to thymol alone. Therefore, we selected oregano EO for nanoemulsion formulation and tested it in vivo as a topical anti-acne treatment.

\subsection{Nanoemulsion Formulation of Oregano EO}

EOs exhibit poor water solubility, hindering their application in aqueous formulations. $\mathrm{O} / \mathrm{W}$ nanoemulsion of oregano $\mathrm{EO}$ was formulated to improve its poor water solubility. It contained less than $5 \%(w / w)$ of oregano EO and Pluronic F127, exhibiting a clear stable solution. The nano formulation stability was assessed for four weeks at room temperature. No signs of cloudiness, creaming or phase separation were observed. The prepared nanoemulsion had a particle size of $39.54 \mathrm{~nm}$, with a polydispersity index of 0.285 , indicating its low size distribution. Figure S2 shows the results of mean droplet size and polydispersity index of the prepared nanoemulsion.

\subsection{Assessment of In Vivo Antimicrobial and Healing Activities of Oregano EO Nanoemulsion Using In Vivo Acne Mouse Model}

Oil dose was adjusted in the formulation at $2 \mathrm{MIC}$ as $0.672 \mathrm{mg} / \mathrm{mL}$ in order to avoid possible irritation or hypersensitive skin reaction. We assessed the anti-acne activity of the formulated nanoemulsion of oregano EO using in vivo acne mouse model. We infected BALB/c mice ears intradermally with P. acnes. After two days, nano formulation or $2 \%$ erythromycin epicutanously was applied on mice ears and measured anti-inflammatory and antimicrobial activity against $P$. acnes. A third group of mice was injected with phosphate buffered saline (PBS) without P. acnes as a healthy control group. Mice of the uninfected ear control group had no detectable bacterial growth. We also evaluated healing by examining histopathology of mouse ear tissue. We compared results to mice treated with $2 \%$ erythromycin (positive controls) and untreated mice (negative controls). Nanoemulsion of oregano EO significantly reduced inflammation at the end of the experiment (Figure 4). The percentage inhibition of inflammation for all animal groups was calculated using the following formula [14]:

$$
\% \text { inflammation inhibition }=\frac{\% \text { inhibition }(\text { control })-\% \text { inhibition }(\text { treatment })}{\% \text { inhibition }(\text { control })}
$$

Inhibition of inflammation at the end of the experiment was significantly lower in mice treated with nanoemulsion compared to the positive control erythromycin (Figure 4). Moreover, the rate of reduction of mice ear thickness, post treatment, was also superior to erythromycin positive control (Figure 5).

The in vivo antimicrobial activity of oregano EO nanoemulsion was assessed where bacterial counts of $P$. acnes dropped from $1 \times 10^{8}$ to $4.3 \times 10^{1} \mathrm{CFU} / \mathrm{mL}$ post-treatment with $0.672 \mathrm{mg} / \mathrm{mL}$ of oregano nanoemulsion (Figure 6). In contrast, the bacterial number for the negative control group (treated with PBS buffer) was maintained at $5 \times 10^{5} \mathrm{CFU} / \mathrm{mL}$, whereas the positive control treated with erythromycin solution reduced the bacterial number to $3.5 \times 10^{3} \mathrm{CFU} / \mathrm{mL}$.

Finally, we assessed the healing effects of oregano EO nanoemulsion using histopathological and digital photography. Infected mice ears treated with nanoemulsion showed healing comparable to the erythromycin positive control, resembling normal ear tissue. Our in vivo results collectively suggested that oregano nanoemulsion effectively killed P. acnes and healed ear tissue inflammation better than erythromycin, the standard antibiotic for acne. 


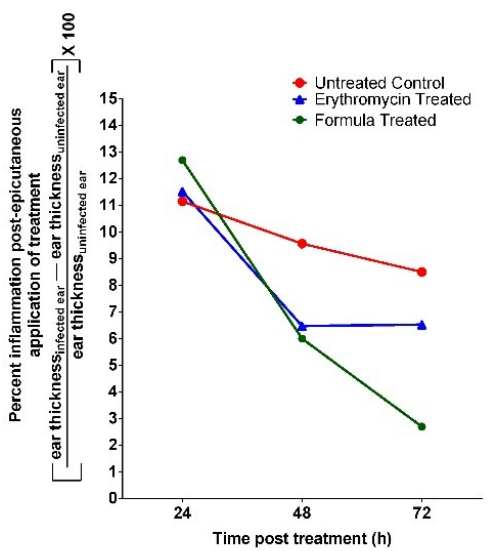

(a)

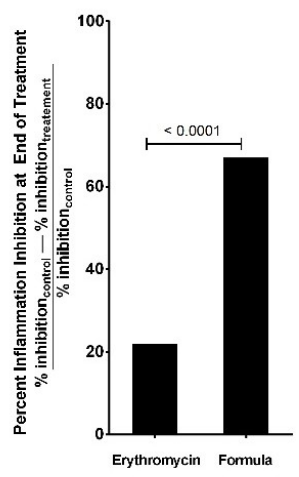

(b)

Figure 4. Oregano EO nanoemulsion showed stronger inhibition of inflammation than erythromycin control in acne mouse model. The acne mouse model was induced by intradermal injection of BALB/c mice's left ears with $10^{8} \mathrm{CFU}$ in $20 \mathrm{~mL}$ of P. acnes. The mice's right ears served as uninfected control. We applied epicutanously either oregano EO nanoemulsion or 2\% Erythromycin solution on the infected mice ears. A third group of mice served as untreated control. (a) Percent inflammation was assessed post epicutaneous application of treatment as the difference between each mouse ear thickness of infected and uninfected ears. Oregano nanoemulsion showed higher rate of reduction in inflammation than $2 \%$ erythromycin during the treatment time interval. (b) Oregano nanoemulsion showed significantly higher percent of inhibition of inflammation $(>60 \%)$ at the end of treatment period than $2 \%$ erythromycin control (20\%). Data represented as mean \pm standard deviation of three independent experiments, total mice per group 15 mice. We used $t$-test for comparing groups with $p<0.05$ consider significant.

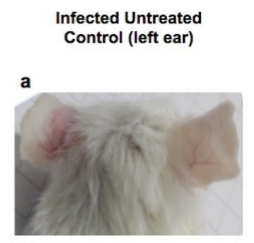

d

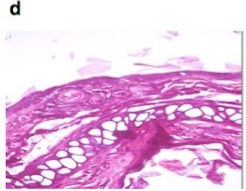

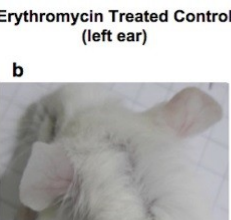

f

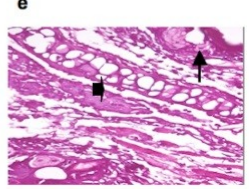

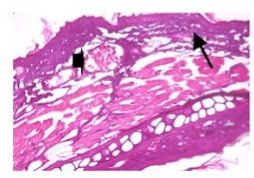

Formula Treated (left ear)
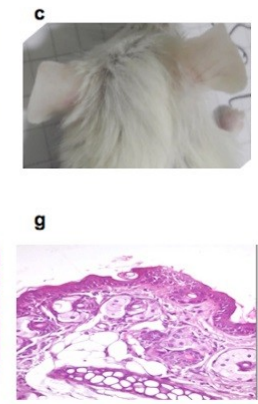

Figure 5. Oregano nanoemulsion as a potent anti-acne agent tested in vivo model of P. acnes infection Photo images of BALB/c mice ear skin at the end of the experiment showing (a) untreated control mice, one ear injected with $20 \mu \mathrm{L}$ of $10^{8} \mathrm{CFU}$ P. acnes suspension showing microcomedones and inflammation in infected left ear compared to the uninfected right ear; (b) inflammation in left infected ear disappeared after treatment with erythromycin solution comparable to the right uninfected ear; (c) absence of inflammatory appearance in left infected ear treated by oregano formula; (d) histopathological analysis of uninfected mice ear skin tissue stained with hematoxylin and eosin showing normal histology of mouse ear tissue with basal layer and epidermal cell maturation preserved; (e) histopathology of infected untreated control mice ear showing necrotic dermatitis character; note the severe dermal necrosis (arrow head), and lymphocytic infiltrate (arrow); (f) ear showing acute dermatitis character; note the congested blood vessels (arrow head), and slight lymphocytic cells infiltration (arrow) treated by erythromycin solution; (g) ear showing apparently normal histology of mouse ear tissue with the absence of inflammatory reaction, treated with oregano formula. 


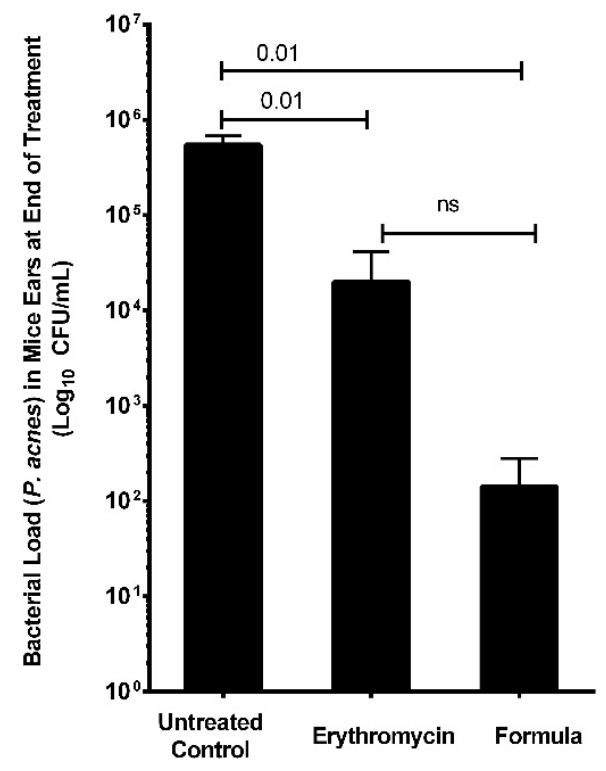

Figure 6. Oregano EO nanoemulsion showed higher antimicrobial effect against $P$. acnes than erythromycin control in acne mouse model. We induced acne in a mouse model by intradermal injection of BALB/c mice left ears with $10^{8} \mathrm{CFU}$ in $20 \mu \mathrm{L}$ of $P$. acnes. The mice's right ears served as uninfected control. We applied epicutanously either oregano EO nanoemulsion or $2 \%$ Erythromycin solution on infected mice ears. A third group of mice served as untreated control. Viable counts of $P$. acnes load in mice ears at the end of the treatment of various mice groups were performed. Oregano nanoemulsion significantly lowered bacterial load in treated mice ears than $2 \%$ Erythromycin. Bacterial load was expressed as $\log _{10} \mathrm{CFU} / \mathrm{mL}$. Data represented as mean \pm standard deviation of three independent experiments, total mice per group 15 mice. T-test was used for comparing groups with $p<0.05$ considered significant.

\section{Discussion}

Oregano EO exhibited the strongest antimicrobial effect against the tested acne-causing bacteria. Using disc diffusion, MIC, and MBC assays, oregano, thyme, and thymol were the top three antimicrobial agents against $P$. acnes. Meanwhile, tea tree and lemongrass EOs exhibited an intermediate antimicrobial effect against $P$. acnes and S. epidermidis. Both tested acne-causing bacteria were resistant to chamomile, lavender, and menthe EOs. Thus, in this study, the anti-acne effects of oregano EO surpassed that of other EOs evaluated including commercialized over-the-counter acne treatment tea tree EO $[15,16]$. Moreover, part of acne pathogenesis includes S. epidermidis biofilm formation. Bacteria growing in biofilms are more resistant to antibiotics compared to planktonic lifestyle [17]. Therefore, we assessed the anti-biofilm ability of the most potent antimicrobial EOs and found that oregano EO exhibited strongest anti-biofilm activity. Moreover, oregano EO at 4 MIC showed rapid killing of both tested acne-causing bacteria.

Thymol exhibited potent antimicrobial activity against acne-causing bacteria, but less than oregano EO itself. Thymol exhibits significant bactericidal activity [18-20] and reduces bacterial resistance to antibiotics [21]. Thymol antimicrobial action is mainly mediated via inhibiting bacterial growth and lactate production, decreasing cellular glucose uptake, causing lysis of fungal hyphal wall [22,23]. Thymol was the principal phenolic component of oregano EO $(>99 \%)$ and thyme $\mathrm{EO}(>70 \%)$. It is thus suggested for its role in mediating the EOs' antimicrobial effect. However, thymol alone was less potent than oregano EO. It could be that other minor volatiles present at lower levels such as $p$-cymene, $\gamma$-terpinene, $\alpha$-thujene and cineole synergized thymol's effect in oregano EO and may account for difference in activity between oregano and thymol. Composition of EOs depends on a number of factors, including harvesting seasons, plant cross-section, extraction method, and geographical sources 
(reviewed in [24]). This can account for differences between results obtained from different studies, where variation in thymol amount is significant $[25,26]$. The EOs used in this study were obtained from plants collected during the flowering stage, which could explain the high phenolic compound levels. Collectively, oregano EO was the most potent antimicrobial. Consequently, it was formulated in nanoemulsion topical dosage form to be assessed as anti-acne formula in vivo on acne-induced mouse model.

Treatment of the acne mouse model with proposed oregano nanoemulsion resulted in reduction of inflammation, bacterial load and healing of tissue superior to erythromycin. EOs' antibacterial effects are improved through formulation as nanoemulsions [27-29]. The prepared emulsion had a particle size of $39.54 \mathrm{~nm}$ and a polydispersity index of 0.285 , indicating its low size distribution; it is, therefore, considered as a nanoemulsion [30]. Pluronic F127 surfactant was used at a concentration of $4.5 \%$ and the oil at $0.5 \% w / w$. The used concentration is above Pluronic F127 critical micelle concentration (CMC), where CMC of Pluronic F127 ranges between $0.26-0.8 \mathrm{wt} \%$. Oregano oil exhibited anti-inflammatory, anti-leishmanial, antioxidant, hepatoprotective and anti-tumor activities, reviewed in [31]. To the best of our knowledge, this is the first study to report the anti-acne effect of oregano EO. Oregano's anti-acne effects surpass those of the commercialized over-the-counter acne tea tree EO and select EOs with documented anti-microbial effects [11]. Most animals do not produce sufficient triglycerides to harbor P. acnes [32]. Therefore, we standardized our acne mouse model using BALB/c mice through intradermal injection of $P$. acnes in mice ears [32,33]. Based on our in vivo results, we propose BALB/c mice as another possible mouse strain for the development of an animal model of acne.

The essential oils of aromatic plants offer spasmolytic, mucolytic and cough soothing effects $[31,34]$. In addition, antimicrobial effects of EOs against pathogens and food contaminants have also been favored due to the safety of natural-origin products, preferred by the public [35]. Little attention, however, has been paid to EO's antimicrobial effect against acne-causing bacteria. Overall, our results indicate that the proposed oregano nanoemulsion exhibits high antimicrobial and healing effects with fewer side-effects than anti-acne reference antibiotics. The potential use of our proposed oregano nanoemulsion as an anti-acne agent opens the field for new alternative treatments of natural origin, avoiding the problems associated with the use of antibiotics for acne. Further clinical studies on our proposed formulation can increase its potential as a drug to be used clinically in humans.

\section{Materials and Methods}

\subsection{Essential Oils}

Seven EOs were used in this study, viz., oregano (Origanum vulgare), thyme (Thymus vulgaris), lemongrass (Cymbopogon citratus), tea tree (Melaleuca alternifolia), mentha (Mentha piperita), lavender (Lavendula anguestifolia) and chamomile (Matricaria recutita). The pharmaceutical grade EOs were kindly provided as a gift from the Department of Food Science and Technology, Nebraska University, Lincoln, NE, USA. We determined the composition of oregano and thyme EOs by GC-MS analysis at the Department of Pharmacognosy, Faculty of Pharmacy, Cairo University, as detailed in Section 4.8. Pure thymol was purchased from Sigma Aldrich, St. Louis, MO, USA.

\subsection{Bacterial Strains and Culturing}

Propionibacterium acnes ATCC 6919 and Staphylococcus epidermidis ATCC 28319 were kindly provided by Dr. Mayri A. Diaz, Manchester University, UK. S. epidermidis was cultured aerobically on brain heart infusion (BHI) agar (LAB M limited, Lancashire, UK) and incubated at $37{ }^{\circ} \mathrm{C}$ for $18 \mathrm{~h}$. We sub-cultured isolated colonies of S. epidermidis in BHI broth and incubated at $37^{\circ} \mathrm{C}$ for $18 \mathrm{~h}$ aerobically. For $P$. acnes, we cultured the bacteria anaerobically on reinforced clostridial medium (RCM) agar (Oxoid Limited, Basingstoke, UK) for $48 \mathrm{~h}$ at $37^{\circ} \mathrm{C}$ and $\sim 5 \% \mathrm{CO}_{2}$ using anaerobic jar and anaerobic atmosphere generation bags (Sigma-Aldrich, St. Louis, MO, USA). We sub-cultured isolated colonies of $P$. acnes in RCM broth for $48 \mathrm{~h}$ at $37^{\circ} \mathrm{C}$ under anaerobic conditions. 


\subsection{Animals}

Male BALB /c mice ( 6 weeks old, $20 \mathrm{~g}$ of weight) $(n=50$ mice) were purchased from Theodor Bilharz Research Institute (Giza, Egypt). Research procedures were conducted in compliance with the principles and recommendations of the Guide for the Care and Use of Laboratory Animals Association, A.V.M. (2007) [36]. All animal experiments were approved by the research ethics committee of the Faculty of Pharmacy, Cairo University, protocol identification code (MI2002); date of approval: 30 May 2017.

\subsection{Screening of Antibacterial Activities of EOs by Disc Diffusion Method}

As a preliminary screening step, the antibacterial activities of all seven EOs was determined using agar disc diffusion, according to the Kirby-Bauer method [37] with some modification. EOs were diluted in analytical grade sterilized dimethylsulfoxide (DMSO) (Sigma Aldrich, St. Louis, MO, USA) and stock solutions of each of the oils at a concentration of $0.7 \%$ and $1.4 \%$ were prepared. We filter sterilized the prepared stock solutions by sterile syringe filter $0.2 \mu \mathrm{m}$ (Corning, New York, NY, USA). Using the culturing method (detailed in Section 4.2), we prepared cell suspensions of S. epidermidis and P. acnes cultures at bacterial density adjusted to $10^{8} \mathrm{CFU} / \mathrm{mL}$. We spread bacterial suspensions on BHI or RCM agar plates for testing EOs against $S$. epidermidis or P. acnes, respectively. We immersed sterile filter-paper discs in $20 \mu \mathrm{L}$ (EOs and DMSO) at either $0.7 \%$ or $1.4 \%$ and placed discs on the surface of the agar until dry; they were then incubated under appropriate conditions detailed for each bacterium above. We used two standard reference antibiotics clindamycin $(2 \mu \mathrm{g} / \mathrm{disc})$ and erythromycin $(15 \mu \mathrm{g} /$ disc $)$ as reference controls, and we used DMSO as a negative control. We evaluated the antibacterial activity of each $\mathrm{EO}$ at each concentration by measuring the zone of inhibition diameter by Vernier's caliper expressed in millimeters $(\mathrm{mm})$. The assays were performed in triplicate and repeated as three independent experiments.

\subsection{Determination of the MIC and $M B C$ of the EOs}

MIC and MBC of the EOs were determined using broth microdilution method in 96 well $\mathrm{U}$ shaped bottom microtiter plates in accordance with Clinical and Laboratory Standards Institute (CLSI) guidelines (2011) [38]. We dissolved EOs in sterilized DMSO at a final concentration of $7 \%(v / v)$, and then performed serial two-fold dilutions from $0.00875-0.56 \%(v / v)$ of the EOs. We prepared an inoculum of S. epidermidis and P. acnes in BHI broth and RCM, respectively, with $\mathrm{OD}_{600 \mathrm{~nm}}$ adjusted to 0.5 . We diluted the inocula to obtain a final turbidity in wells approximately $10^{6} \mathrm{CFU} / \mathrm{mL}$. We incubated aliquots of $50 \mu \mathrm{L}$ of bacteria and $50 \mu \mathrm{L}$ of different concentration of each EO, at $25^{\circ} \mathrm{C}$ for $24 \mathrm{~h}$ for S. epidermidis in aerobic conditions and $37^{\circ} \mathrm{C}$ for $48 \mathrm{~h}$ for P. acnes bacteria under anaerobic conditions. We measured bacterial density changes using ELISA plate reader (InfiniteF50 Tecan-Sweden) at wavelength of $620 \mathrm{~nm}$. We determined the lowest concentration of $\mathrm{EO}$ at which no bacterial density was detected as the MIC of the EO. We tested each EO at each concentration in triplicate and repeated the experiment three independent times. We used $50 \mu \mathrm{L}$ of bacteria-free broth and $50 \mu \mathrm{L}$ DMSO as negative control. For MBC determination, we inoculated $10 \mu \mathrm{L}$ of mixtures of respective bacteria and EOs at different concentrations on agar plates (as detailed above) and determined bacterial counts expressed as $\mathrm{CFU} / \mathrm{mL}$ after incubation at $37^{\circ} \mathrm{C}$ at 24 and $48 \mathrm{~h}$ for S. epidermidis and P. acnes, respectively. We determined $\mathrm{MBC}$ as the lowest concentration of the $\mathrm{EO}$ at which incubated respective bacteria showed no detectable colonies on respective agar plates. To determine MBC, we tested each EO at each concentration in triplicate and repeated the experiment three independent times.

\subsection{Minimum Biofilm Inhibitory Concentration (MBIC)}

We determined MBIC for EOs against S. epidermidis biofilm using the microtiter plate method, as described previously [39], with some modifications. Briefly, we incubated $100 \mu \mathrm{L}$ of S. epidermidis at $10^{8} \mathrm{CFU} / \mathrm{mL}$ in BHI- $1 \%$ glucose $(w / v)$ with $100 \mu \mathrm{L}$ of the EO concentrations $0.00875-0.56 \%(v / v)$ 
at $25{ }^{\circ} \mathrm{C}$ for $24 \mathrm{~h}$. Following incubation, we removed the contents of each well and gently rinsed the wells twice with $300 \mu \mathrm{L}$ of PBS. We air dried the plate for $30 \mathrm{~min}$ and stained the formed biofilm with $0.1 \%(w / v)$ crystal violet $(\mathrm{CV})$ for $30 \mathrm{~min}$ at room temperature. We then washed the excess $\mathrm{CV}$ from the plate with $200 \mathrm{~mL}$ of PBS per well, repeated washing three times and air-dried the plate. To measure the biofilm stained with CV, we solubilized CV using $95 \%(v / v)$ ethanol and measured the $\mathrm{CV}$ color intensity at $\mathrm{OD}_{595 \mathrm{~nm}}$ using a Microplate reader (Infinite F50 Tecan). We determined MBIC for oregano, thyme, lemongrass, tea tree EOs, and thymol. We used BHI broth as a negative control and S. epidermidis cell culture without EOs as a positive control. We determined MBIC as the EO concentration at which the $\mathrm{OD}_{595 \mathrm{~nm}}$ is equal to that of the negative control. Experiments for each EO concentration were performed in triplicate and the assay was repeated three independent times.

\subsection{Determination of Kill Kinetics}

Time-kill kinetics assay was performed for oregano EO against S. epidermidis and P. acnes as described previously [40]. Bacterial suspensions at a final concentration of $10^{8} \mathrm{CFU} / \mathrm{mL}$ were used as the initial inoculum. We assayed oregano EO killing time at concentrations of $\mathrm{mg} / \mathrm{mL}(0.035 \%), \mathrm{mg} / \mathrm{mL}$ $(0.07 \%)$, and $\mathrm{mg} / \mathrm{mL}(0.14 \%)$ equivalent to 1,2 , and 4 MIC. We incubated different concentrations of oregano EO with the two bacterial cultures and measured killing capacity at $0,1,2,4,8,12$, and $24 \mathrm{~h}$ using broth micro-dilution method. At each time point, we used $50 \mu \mathrm{L}$ of the assay solution to make ten-fold serial dilutions and performed viable counts on BHI and RCM agar plates for the respective bacteria. We incubated the agar plates at $25{ }^{\circ} \mathrm{C}$ for $24 \mathrm{~h}$ under aerobic conditions and $37{ }^{\circ} \mathrm{C}$ under anaerobic conditions for $48 \mathrm{~h}$ for each respective bacterium. We expressed viable count of each bacterium as CFU/mL. We used DMSO solvent and equivalent broth as negative controls. Each concentration of EO was assayed as triplicate and the entire assay was repeated three independent times.

\subsection{Gas Chromatography-Mass Spectroscopy}

We analyzed the chemical components of oregano and thyme EOs using gas chromatographymass spectrometry (GC-MS) on a Shimadzu Model GC-17A gas chromatograph interfaced with a Shimadzu model QP-5000 mass spectrometer (Shimadzu, Kyoto, Japan). We separated volatiles on a DB5-MS column with specifications: $30 \mathrm{~m}$ length, $0.5 \mathrm{~mm}$ i.d., and $0.25 \mu \mathrm{m}$ film (J\&W Scientific, Santa Clara, CA, USA). We injected the EOs at a split ratio of 1:10 for the $30 \mathrm{~s}$. We used the following operating conditions: Injector $220^{\circ} \mathrm{C}$, column oven $38^{\circ} \mathrm{C}$ for $3 \mathrm{~min}$, then programmed at a rate of $12{ }^{\circ} \mathrm{C} \mathrm{min}{ }^{-1}$ to $220^{\circ} \mathrm{C}$ and kept for $2 \mathrm{~min}$, His carrier gas at $1 \mathrm{~mL} \mathrm{~min}^{-1}$. We adjusted the transfer line and ion-source temperatures to 230 and $180{ }^{\circ} \mathrm{C}$, respectively. We operated the HP quadrupole mass spectrometer in the electron ionization mode at $70 \mathrm{eV}$ and set the scan range at $m / z 40-500$. We identified the volatile components using the procedures described previously [41]. We identified the resultant peaks after first de-convoluted using AMDIS software (www.amid.net) and we subsequently identified the compounds by their retention indices (RI) relative to n-alkanes (C6-C20), and by matching their mass spectra to the NIST, WILEY library database ( $>90 \%$ match) as well as to those of authentic standards when available.

\subsection{Development of Nanoemulsion}

A low energy method was used for preparation of oregano nanoemulsion [42], using 95\% (w/w) of water, $5 \%(w / w)$ mixture of EO and Pluronic F127. The EO and surfactant mixture was prepared at a concentration of $4.5 \%$ of Pluronic F127 and the oil at $0.5 \% w / w$. We added the defined amounts of oregano oil and Pluronic F127 and mixed by stirring at $800 \mathrm{rpm}$ for $30 \mathrm{~min}$. A stable nanoemulsion was formed by adding water drop wise at $3.5 \mathrm{~mL} / \mathrm{min}$ flow rate while stirring at $800 \mathrm{rpm}$ for $1 \mathrm{~h}$. We stored the formed nanoemulsion at $25^{\circ} \mathrm{C}$ and observed after $24 \mathrm{~h}$ and 1, 3, and 4 weeks of preparation. The droplet size and polydispersity index of the prepared nanoemulsion were measured using photon 
correlation spectroscopy (Zetasizer ZS, Malvern, UK). We expressed the mean diameter of the droplet size in $\mu \mathrm{m}$ and all measurements were made in triplicates.

\subsection{In Vivo Antiacne Experiment}

An initial preliminary experiment $(n=5 \mathrm{BALB} / \mathrm{c}$ mice) to examine the possible irritability of the oregano nanoemulsion was performed. In this preliminary experiment, we applied epicutanously $10 \mu \mathrm{L}$ nanoemulsion (2 MIC against P. acnes as calculated by our in vitro assays) on ears of a group of healthy uninfected mice and observed over 5 days for any signs of inflammation.

In our in vivo experiments for assessment of oregano nanoemulsion efficacy, we used $45 \mathrm{BALB} / \mathrm{c}$ male mice divided into three groups ( $n=5$ mice/group/experiment). We measured mice ear thickness prior to injections, then, we injected mice the right ears intradermally with $20 \mu \mathrm{L}$ PBS (healthy control ear) using Hamilton syringe $50 \mu \mathrm{L}$ model $705 \mathrm{RN}$ (Hamilton Co., Reno, NV, USA). We induced acne infection and inflammation by injecting the left ear with $20 \mu \mathrm{L}$ of $10^{8} \mathrm{CFU}$ P. acnes according to previously established protocol [43]. We observed the mice for microcomedones formation for 24-72 $\mathrm{h}$ and measured daily changes in ear thickness using electronic digital micrometer caliper (0-25 mm/0.001 mm). We considered appearance of microcomedones and the increase in mice ear thickness $\geq 10 \%$ as indicators of acne induction [43]. For infected mice ears, we applied epicutanously either $20 \mu \mathrm{L}$ of $2 \mathrm{MIC}$ oregano formulated nanoemulsion (test group), or $2 \%$ erythromycin (positive control), or no treatment (negative control) for 3 days. We recorded daily changes in mice ear thickness, weight, and took digital photographs of mice ears. At the end of the experiment, we excised mice ears and performed viable bacterial counts and histopathological assay.

We calculated percent inflammation post epicutaneous application of treatment for all the animal groups using the following formula:

$$
\% \text { inflammation }=\frac{\text { ear thickness }(\text { infected ear })-\text { ear thickness }(\text { uninfected ear })}{\text { ear thickness }(\text { infected ear })}
$$

We calculated the percentage inhibition of inflammation for all the animal groups using the following formula as described previously [14]:

$$
\% \text { inflammation inhibition }=\frac{\% \text { inhibition }(\text { control })-\% \text { inhibition }(\text { treatment })}{\% \text { inhibition }(\text { control })}
$$

For histological examination, we preserved whole excised mice ears in $10 \%$ formalin-saline solution before preparing the histological sections using paraffin method technique. We dehydrated all sections in ascending grades of ethanol, cleared in xylene and then embedded in paraffin wax. We mounted transverse sections (4-5 micron, thickness) on glass slides and stained with hematoxylin and eosin (H\&E) stains. We examined all sections for the evaluation of inflammatory response.

For in vivo assessment of anti-microbial activity of our nanoemulsion, we homogenized excised mice ears in PBS, then cultured the homogenates using plating serial dilutions method on RCM agar plates and counted P. acnes after $72 \mathrm{~h}$ of anaerobic incubation at $37^{\circ} \mathrm{C}$.

\subsection{Statistical Analyses}

All data were recorded in Excel worksheets (Microsoft Office 2010). Results were analyzed and plotted using both Microsoft Excel and Graph Pad Prism program (Version 6.1). The data presented is at least three independent experiments as mean \pm standard deviation. For evaluation of statistical significance, $t$-test and one-way ANOVA test with Turkey's multiple comparisons was used and considered $p \leq 0.05$ significance level.

Supplementary Materials: The following are available online. Table S1: Zone of inhibition (mm) against S. epidermidis and P. acnes; Figure S1: GC-MS chromatogram analysis of (a) oregano oil, (b) thyme oil; Figure S2: Size distribution by the intensity of the developed oregano nanoemulsion. 
Author Contributions: Conceptualization, M.H.T., R.N.S., N.F.A. and M.A.R.; Methodology, M.H.T., N.F.A. and S.S.M.; Validation, M.H.T., N.F.A. and S.S.M. Formal Analysis, M.H.T., R.N.S. and N.F.A.; Investigation, M.H.T., R.N.S., N.F.A, S.S.A., S.S.M. and M.A.F.; Resources, M.H.T., R.N.S., N.F.A. and M.A.F.; Data Curation, M.H.T. and N.F.A.; Writing-Original Draft Preparation, M.H.T. and N.F.A.; Writing-Review \& Editing, M.H.T., R.N.S., N.F.A, S.S.A., S.S.M., M.A.F. and M.A.R.; Visualization, M.H.T., R.N.S., N.F.A, S.S.A. and M.A.F.; Supervision, R.N.S., N.F.A. and M.A.R.; Project administration, N.F.A. and M.A.R.

Funding: This research received no external funding.

Acknowledgments: The authors are grateful to Mayri A. Diaz De Rienzo, Liverpool John Moores University: Liverpool, Liverpool, United Kingdomand Hesham Salman, Bionanoplus Company, Spain for providing the bacterial standard strain studied in this research. We are also grateful for Rami Ziara, Nebraska University-Lincoln, Nebraska, USA, for providing pharmaceutical grade essential oils for the study. Farag acknowledges the funding received from Alexander von Humboldt foundation, Germany to his laboratory.

Conflicts of Interest: The authors declare no conflict of interest.

\section{References}

1. Vos, T.; Flaxman, A.D.; Naghavi, M.; Lozano, R.; Michaud, C.; Ezzati, M.; Shibuya, K.; Salomon, J.A.; Abdalla, S.; Aboyans, V.; et al. Years lived with disability (YLDs) for 1160 sequelae of 289 diseases and injuries 1990-2010: A systematic analysis for the Global Burden of Disease Study 2010. Lancet 2012, 380, $2163-2196$. [CrossRef]

2. Hull, P.R.; D'Arcy, C. Acne, depression, and suicide. Dermatol. Clin. 2005, 23, 665-674. [CrossRef] [PubMed]

3. Williams, H.C.; Dellavalle, R.P.; Garner, S. Acne vulgaris. Lancet 2012, 379, 361-372. [CrossRef]

4. Nishijima, S.; Kurokawa, I.; Katoh, N.; Watanabe, K. The bacteriology of acne vulgaris and antimicrobial susceptibility of Propionibacterium acnes and Staphylococcus epidermidis isolated from acne lesions. J. Dermatol. 2000, 27, 318-323. [CrossRef] [PubMed]

5. Chularojanamontri, L.; Tuchinda, P.; Kulthanan, K.; Pongparit, K. Moisturizers for acne: What are their constituents? J. Clin. Aesthet. Dermatol. 2014, 7, 36-44. [PubMed]

6. Patel, M.; Bowe, W.P.; Heughebaert, C.; Shalita, A.R. The development of antimicrobial resistance due to the antibiotic treatment of acne vulgaris: A review. J. Drugs Dermatol. JDD 2010, 9, 655-664. [PubMed]

7. Kinney, M.A.; Yentzer, B.A.; Fleischer, A.B., Jr.; Feldman, S.R. Trends in the treatment of acne vulgaris: Are measures being taken to avoid antimicrobial resistance? J. Drugs Dermatol. JDD 2010, 9, 519-524. [PubMed]

8. Högberg, L.D.; Heddini, A.; Cars, O. The global need for effective antibiotics: Challenges and recent advances. Trends Pharmacol. Sci. 2010, 31, 509-515. [CrossRef] [PubMed]

9. Burt, S. Essential oils: Their antibacterial properties and potential applications in foods-A review. Int. J. Food Microbiol. 2004, 94, 223-253. [CrossRef] [PubMed]

10. Mancini, E.; Camele, I.; Elshafie, H.S.; de Martino, L.; Pellegrino, C.; Grulova, D.; de Feo, V. Chemical composition and biological activity of the essential oil of Origanum vulgare ssp. hirtum from different areas in the Southern Apennines (Italy). Chem. Biodivers. 2014, 11, 639-651. [CrossRef] [PubMed]

11. Sinha, P.; Srivastava, S.; Mishra, N.; Yadav, N.P. New perspectives on antiacne plant drugs: Contribution to modern therapeutics. BioMed Res. Int. 2014, 2014, 301304. [CrossRef] [PubMed]

12. González-Tejero, M.; Casares-Porcel, M.; Sánchez-Rojas, C.; Ramiro-Gutiérrez, J.; Molero-Mesa, J.; Pieroni, A.; Giusti, M.; Censorii, E.; de Pasquale, C.; Della, A. Medicinal plants in the Mediterranean area: Synthesis of the results of the project Rubia. J. Ethnopharmacol. 2008, 116, 341-357. [CrossRef] [PubMed]

13. McClements, D.J. Nanoemulsions versus microemulsions: Terminology, differences, and similarities. Soft Matter 2012, 8, 1719-1729. [CrossRef]

14. Budhiraja, A.; Dhingra, G. Development and characterization of a novel antiacne niosomal gel of rosmarinic acid. Drug Deliv. 2015, 22, 723-730. [CrossRef] [PubMed]

15. Bassett, I.; Pannowitz, D.; Barnetson, R. A comparative study of tea-tree oil versus benzoylperoxide in the treatment of acne. Med. J. Aust. 1990, 153, 455-458. [PubMed]

16. Enshaieh, S.; Jooya, A.; Siadat, A.H.; Iraji, F. The efficacy of 5\% topical tea tree oil gel in mild to moderate acne vulgaris: A randomized, double-blind placebo-controlled study. Indian J. Dermatol. Venereol. Leprol. 2007, 73, 22-25. [PubMed] 
17. Fey, P.D.; Olson, M.E. Current concepts in biofilm formation of Staphylococcus epidermidis. Future Microbiol. 2010, 5, 917-933. [CrossRef] [PubMed]

18. Borugă, O.; Jianu, C.; Mişcă, C.; Goleț, I.; Gruia, A.; Horhat, F. Thymus vulgaris essential oil: Chemical composition and antimicrobial activity. J. Med. Life 2014, 7, 56-60. [PubMed]

19. Solórzano-Santos, F.; Miranda-Novales, M.G. Essential oils from aromatic herbs as antimicrobial agents. Curr. Opin. Biotechnol. 2012, 23, 136-141. [CrossRef] [PubMed]

20. Ouattara, B.; Simard, R.E.; Holley, R.A.; Piette, G.J.-P.; Bégin, A. Antibacterial activity of selected fatty acids and essential oils against six meat spoilage organisms. Int. J. Food Microbiol. 1997, 37, 155-162. [CrossRef]

21. Abreu, A.C.; McBain, A.J.; Simoes, M. Plants as sources of new antimicrobials and resistance-modifying agents. Nat. Prod. Rep. 2012, 29, 1007-1021. [CrossRef] [PubMed]

22. Böhme, K.; Barros-Velázquez, J.; Calo-Mata, P.; Aubourg, S.P. Antibacterial, antiviral and antifungal activity of essential oils: Mechanisms and applications. In Antimicrobial Compounds; Springer: Berlin, Germany, 2014; pp. 51-81.

23. Elshafie, H.S.; Mancini, E.; Sakr, S.; de Martino, L.; Mattia, C.A.; de Feo, V.; Camele, I. Antifungal activity of some constituents of Origanum vulgare L. essential oil against postharvest disease of peach fruit. J. Med. Food 2015, 18, 929-934. [CrossRef] [PubMed]

24. Figueiredo, A.C.; Barroso, J.G.; Pedro, L.G.; Scheffer, J.J. Factors affecting secondary metabolite production in plants: Volatile components and essential oils. Flavour Fragr. J. 2008, 23, 213-226. [CrossRef]

25. Teixeira, B.; Marques, A.; Ramos, C.; Neng, N.R.; Nogueira, J.M.; Saraiva, J.A.; Nunes, M.L. Chemical composition and antibacterial and antioxidant properties of commercial essential oils. Ind. Crops Prod. 2013, 43, 587-595. [CrossRef]

26. Gavaric, N.; Mozina, S.S.; Kladar, N.; Bozin, B. Chemical profile, antioxidant and antibacterial activity of thyme and oregano essential oils, thymol and carvacrol and their possible synergism. J. Essent. Oil Bear. Plants 2015, 18, 1013-1021. [CrossRef]

27. Ghaderi, L.; Moghimi, R.; Aliahmadi, A.; McClements, D.J.; Rafati, H. Development of antimicrobial nanoemulsion-based delivery systems against selected pathogenic bacteria using a thymol-rich Thymus daenensis essential oil. J. Appl. Microbiol. 2017, 123, 832-840. [CrossRef] [PubMed]

28. Elshafie, H.S.; Camele, I. An Overview of the Biological Effects of Some Mediterranean Essential Oils on Human Health. BioMed Res. Int. 2017, 2017, 9268468. [CrossRef] [PubMed]

29. Elshafie, H.S.; Armentano, M.F.; Carmosino, M.; Bufo, S.A.; de Feo, V.; Camele, I. Cytotoxic activity of Origanum vulgare L. on hepatocellular carcinoma cell line HepG2 and evaluation of its biological activity. Molecules 2017, 22, 1435. [CrossRef] [PubMed]

30. Gao, Q.; Liang, Q.; Yu, F.; Xu, J.; Zhao, Q.; Sun, B. Synthesis and characterization of novel amphiphilic copolymer stearic acid-coupled F127 nanoparticles for nano-technology based drug delivery system. Colloids Surf. B Biointerfaces 2011, 88, 741-748. [CrossRef] [PubMed]

31. Sharifi-Rad, J.; Sureda, A.; Tenore, G.C.; Daglia, M.; Sharifi-Rad, M.; Valussi, M.; Tundis, R.; Sharifi-Rad, M.; Loizzo, M.R.; Ademiluyi, A.O. Biological activities of essential oils: From plant chemoecology to traditional healing systems. Molecules 2017, 22, 70. [CrossRef] [PubMed]

32. Jang, Y.H.; Lee, K.C.; Lee, S.-J.; Kim, D.W.; Lee, W.J. HR-1 Mice: A new inflammatory acne mouse model. Ann. Dermatol. 2015, 27, 257-264. [CrossRef] [PubMed]

33. Li, J.L.; Goh, C.C.; Keeble, J.L.; Qin, J.S.; Roediger, B.; Jain, R.; Wang, Y.; Chew, W.K.; Weninger, W.; Ng, L.G. Intravital multiphoton imaging of immune responses in the mouse ear skin. Nat. Protoc. 2012, 7, 221-234. [CrossRef] [PubMed]

34. Horváth, G.; Ács, K. Essential oils in the treatment of respiratory tract diseases highlighting their role in bacterial infections and their anti-inflammatory action: A review. Flavour Fragr. J. 2015, 30, 331-341. [CrossRef]

35. Chandra, H.; Bishnoi, P.; Yadav, A.; Patni, B.; Mishra, A.P.; Nautiyal, A.R. Antimicrobial Resistance and the Alternative Resources with Special Emphasis on Plant-Based Antimicrobials-A Review. Plants 2017, 6, 16. [CrossRef] [PubMed]

36. AVMA-American Veterinary Medical Association. AVMA Guidelines on Euthanasia [Internet]; AVMA: Schaumburg, IL, USA, 2007.

37. Bauer, A.; Kirby, W.; Sherris, J.C.; Turck, M. Antibiotic susceptibility testing by a standardized single disk method. Am. J. Clin. Pathol. 1966, 45, 493-496. [CrossRef] [PubMed] 
38. CLSI. CLSI supplement M100. In Performance Standards for Antimicrobial Susceptibility Testing; Clinical and Laboratory Standards Institute: Wayne, PA, USA, 2007.

39. O'Toole, G.A. Microtiter dish biofilm formation assay. J. Vis. Exp. JoVE 2011, 30, 2437. [CrossRef] [PubMed]

40. Stratton, C.; Weeks, L.; Aldridge, K. Comparison of kill-kinetic studies with agar and broth microdilution methods for determination of antimicrobial activity of selected agents against members of the Bacteroides fragilis group. J. Clin. Microbiol. 1987, 25, 645-649. [PubMed]

41. Farag, M.A.; Wessjohann, L.A. Volatiles profiling in medicinal licorice roots using steam distillation and solid-phase microextraction (SPME) coupled to chemometrics. J. Food Sci. 2012, 77, C1179-C1184. [CrossRef] [PubMed]

42. Ostertag, F.; Weiss, J.; McClements, D.J. Low-energy formation of edible nanoemulsions: Factors influencing droplet size produced by emulsion phase inversion. J. Colloid Interface Sci. 2012, 388, 95-102. [CrossRef] [PubMed]

43. Luo, H.; Lv, X.-D.; Wang, G.-E.; Li, Y.-F.; Kurihara, H.; He, R.-R. Anti-inflammatory effects of anthocyanins-rich extract from bilberry (Vaccinium myrtillus L.) on croton oil-induced ear edema and Propionibacterium acnes plus LPS-induced liver damage in mice. Int. J. Food Sci. Nutr. 2014, 65, 594-601. [CrossRef] [PubMed]

Sample Availability: Samples of the used oregano EO are available from the authors. 